\title{
Simultaneous Effect of Tool Rotation and Dwell Time on Quality of Dissimilar AA5052-Copper Joints Fabricated by Friction Stir Spot Welding
}

\section{Aydin Jadidi}

University of West

Reza Bagherian Azhiri ( $\square$ reza.azhiri@utdallas.edu )

University of Texas at Dallas

Amir Baghdadchi

University of West

Abolfazl Salmani Bideskan

University of Tabriz

\section{Research Article}

Keywords: Friction stir spot welding, Lap joint configuration, Dissimilar joints, Mechanical properties, Intermetallic compound

Posted Date: February 24th, 2021

DOI: https://doi.org/10.21203/rs.3.rs-230388/v1

License: (c) (i) This work is licensed under a Creative Commons Attribution 4.0 International License. Read Full License 


\section{Abstract}

In the present study, lap joints of dissimilar 5052 aluminum alloy and pure copper were fabricated by friction stir spot welding process. The work was aimed to find effect of parameters such as tool rotary speed (1000, 1400 and 2000 RPM) and dwell time (5, 10 and 15s) on microstructure and strength properties of lap joints. Also, statistical models of the quality characteristics were developed to understand which interaction has dominant effect on quality characteristics. Research findings showed that to obtain sound joints with high lap shear strength tool rotary speed of $2000 \mathrm{rpm}$ and dwell time of 5 s should be selected. It provides sufficient heat input and prevents the excessive material softening. On the other hand, to achieve maximum hardness, $2000 \mathrm{rpm}$ tool rotary speed should be chosen to provide enough heat for formation of intermetallic compound and 10s dwell time should be used prevent enough time for microstructure refining. Moreover, from the statistical analyses, it was found that dwell time and tool speed are the significant factor for lap shear strength and hardness, respectively. In order to attain simultaneous maximum strength and hardness, tool speed of $2000 \mathrm{rpm}$ and dwell time of $8 \mathrm{~s}$ should be used. In such condition lap shear strength of $1755 \mathrm{~N}$ and hardness of $77 \mathrm{~V}$ are achieved with desirability of $85 \%$.

\section{Introduction}

Dissimilar joining of copper and aluminum is applicable for industries such as electronic, aerospace, transportation industries and automobile [1]. The goal of addition of aluminum and copper is to achieve light and safe products which work more environmentally friendly and have cheaper cost. Each element of the fabricated joints can satisfy specific demand where aluminum is a low density and cheap alloy; also copper has desired formability and excellent electrical and thermal conductivities.

However, fabrication of sound joints made of aluminum and copper by fusion processes like electrical resistance spot welding (ERSW) is difficult due to difference in physical chemical, chemical, metallurgical and mechanical properties of these alloys [2]. In such condition, hard and brittle intermetallic compound are formed in weld cross section that drastically reduced mechanical properties of the joints. Therefore, solid state joining like explosive welding [3], roll welding [4] and friction based welding [5] have been considered as the qualified welding methods for these metals.

By emerging friction stir welding (FSW) process, problems such as high heat affected zone, formation of brittle structures, melting and degradation of materials which were faced by fusion welding processes in dissimilar joining were overcome. Hence, researchers have focused on use of FSW for dissimilar joining of aluminum to copper. For first time, Murr et al [6] reported joining of aluminum to copper by FSW. They found that defect free joints are difficult to be fabricated by use of this method. Ouyang et al [1] performed an experimental study to join aluminum 6061-T6 to copper by FSW. They showed that complex microstructure with several intermetallic compounds are observed in weld nugget. Xue et al $[7,8]$ studied effects of FSW main parameters and tool offsetting on mechanical properties of dissimilar AA1060 and $\mathrm{Cu}$. They showed that the properties of fabricated joints significantly influenced by 
formation of intermetallic compounds and corresponding thickness. Tan et al [9] performed experimental work to find relationship between microstructure and strength properties of Al-Cu dissimilar joints. They found that by increasing heat generation caused by reduction of travel speed, large amount of copper particles is dispersed in upper surface of the weld nugget zone and causes formation of composite like surface that improves mechanical properties. $\mathrm{Li}$ at al [10] analyzed microstructure and strength properties of the Cu-AA1350 dissimilar butt joints. The research findings showed that vortex-like pattern and lamella structure are formed in the microstructure of the weld nugget. Also, the hardness distribution was higher in copper side than that of aluminum side. Galvao et al $[11,12]$ analyzed influence of tool offsetting on the morphology and structure of dissimilar aluminum 6082 to copper. They found that welding with tool offsetting formation of intermetallic compounds is prevented but metallurgical inconsistencies in the vicinity of advancing side are formed that have detrimental effect on weld strength. Muthu et al [13] analyzed effect of travel speed from 50 to $90 \mathrm{~mm} / \mathrm{min}$ with $10 \mathrm{~mm} / \mathrm{min}$ increment on mechanical properties and microstructure of the joints. They showed that travel speed of 70 and $80 \mathrm{~mm} / \mathrm{min}$ result to appropriate heat input to form sound welds. Also, various researchers showed feasibility of joining of aluminum to copper in lap configuration by friction stir welding by use a long weld line. Saeid et al. [14] used FSW to joint aluminum to copper sheets in lap configuration. They showed that increase in welding travel speed restricts formation of microcracks and intermetallic compound. Zhang et al. [15] applied water cooling method to FSW of lap Al-Cu joints in order to restrict excessive heat input that caused formation of intermetallic compound.

Nevertheless, aluminum and copper joined by FSW in various configuration, fabrication of lap joints of Al5052-Cu by friction stir spot welding (FSSW) has not studied well so far. Hence, the present study focuses on the effect of the FSSW main parameters such as tool rotary speed and dwell time on the microstructure characterization, weld nugget formation, intermetallic compound and relevant mechanical properties. Also, response surface methodology is utilized here to identify which factors has great influence on tensile strength and hardness and to find optimum parameter setting regarding simultaneous maximization of tensile strength and hardness.

\section{Materials And Methods}

The materials used to fabricate joints were made of AA5052 and pure copper with different chemical composition and material properties. Table 1 presents mechanical properties of parent material which obtained through tensile testing and Vickers microhardness analysis. Samples of aluminum and copper were prepared with dimensions of $1 \times 20 \times 100 \mathrm{~mm}^{3}$ and secured in proper position by used of a handmade clamping system. A hot worked tool made of AISI H13 was machined to form cylindrical tool with tapered like pin profile 
Table 1

Mechanical properties of pure copper and AA5052

\begin{tabular}{|lllll|}
\hline Type & YS (MPa) & TS(MPa) & E (\%) & H (V) \\
\hline Pure copper & 120 & 151 & 39 & 105 \\
\hline AA5052 & 131 & 190 & 21 & 92 \\
\hline
\end{tabular}

The FSSW experiments for joining of aluminum to coper in lap joints were conducted on universal milling machine made of TBARIZ corporation. The machine was set up with a clamping system to restrict the elements in secured position. Lap shear strength of the joints was measured by use of SANTAM universal testing machine with speed of $2 \mathrm{~mm} / \mathrm{min}$. The hardness of welded cross section were also measured by means Vickers Mitutoyo microhardness tester.

To analyze microstructure of the weld nugget, welded samples were cut from their cross-sectioned and subjected to metallographic activities such as polishing and etching. The etchants were used in different section of the joint were selected based on composition of material. Optical microscope was utilized to observe the morphology and microstructure of weld samples. In addition, X-ray diffraction (XRD) examination was utilized to find dispersion of parent metal in weld nugget and to find material characterization in friction stir processed zone

To analyze effects of tool rotary speed (1000, 1500 and 2000 RPM) and dwell time (5, 10 and 15s) mechanical properties and material characterization, number of 9 experiments were conducted and values of tensile strength, hardness along with microstructural characterization were measured and observed through aforementioned equipment's. During the experiments, plunge rate and plunge depth were kept constant at the values of $20 \mathrm{~mm} / \mathrm{min}$ and $0.5 \mathrm{~mm}$ respectively.

\section{Results And Discussion}

\subsection{Analyzing weld strength}

Fig. 1 illustrates interaction effect of tool rotary speed and dwell time on lap shear strength of Al-Cu joints. It is seen in the figure that at 1000 RPM rotary speed, an increase in dwell time from 5 to $15 \mathrm{~s}$ causes an $8.3 \%$ increase in weld strength. While at 1500 RPM speed, the weld strength firstly increases about $14 \%$ by increment of dwell time from 5 to $10 \mathrm{~s}$; but, by further increment of dwell time from 10 to 15 s the weld strength decreases about $16.5 \%$. on the other hand, when the tool rotary speed is 2000 RPM, it is seen from the fig. 1 that as dwell time increases, the weld strength decreases continuously about $27 \%$.

When the tool rotary speed is 1000RPM, the heat input in friction stir processed (FSP) region is relatively low [16]. In such condition, by increase in dwell time the concentration of the heat increases that provides enough thermal energy for plasticization and stirring action. Thus, defects such as tunnel due to insufficient heat input is eliminated that causes increase in weld strength. Furthermore, due to 
concentration of more thermal at higher dwell time, the copper metal is softened and its contribution in formation of FSP region enhances. Hence, the weld shear strength increases. Fig. 2 represents macrostructure and microstructure of FSP region that produced at rotational speed of 1000 RPM and different dwell time. It is seen from macrostructure that by increase in dwell time the defect eliminated from weld macrostructure. Also, it is found from the figure that increase in dwell causes formation of further copper particles in FSP region that yields higher weld strength.

When the tool rotary speed is 1500 RPM, it is seen from the fig. 1 that by increase in dwell time from 5 s to 10 s the weld strength increases. As discussed, this improvement is due to providing enough heat input and sufficient material flow in FSP region that removes defect and enhances the weld strength. However, when the dwell time goes beyond a critical value of $10 \mathrm{~s}$, it is seen a drastic reduction occurs in lap shear strength. This decrease is because to the fact that at high dwell time, the thermal energy concentration is excessive that causes material softening. Therefore, by plunging force of the tool, the thickness of aluminum side decreases that results to a reduction in weld strength [17].

Fig. 3 illustrates macrostructure of the weld region at 1500 RPM rotary speed and different dwell time. It is found from the figure that a $5 \mathrm{~s}$ dwell time due to less concentration of thermal energy a tunnel like defect is formed between aluminum and copper in keyhole region. Also, it is found that at 10 s dwell time the defect is eliminated and sound joint is fabricated. On the other hand, it is inferred from fig. $3 \mathrm{c}$ that at $15 \mathrm{~s}$ dwell time due to excessive heat input material softening occurs that causes thickness reduction in aluminum side and formation of pin hole defect in keyhole region that restricts weld strength.

However, it is seen from the fig. 1 that at 2000 RPM tool rotation, by increase in dwell time the weld strength decreases, subsequently. When the tool rotation is 2000 RPM, the heat input is relatively high; hence, at $5 \mathrm{~s}$ dwell time the sufficient thermal energy is provided that is enough for plasticization, stirring action and material flow. However, by increase in dwell time, due to excessive heat input, the material softening occurs in both aluminum and copper that causes a reduction in the thickness of the sheets. In such condition the strength of the lap configuration drastically decreases.

The macroscopic image of weld cross section at 2000RPM rotary speed is visible in fig. 4 It is ascertained from the figure $4 a$ that at $5 \mathrm{~s}$ dwell time the macrostructure is free from defect and thinning in the thickness. While, at 10 and $15 \mathrm{~s}$ dwell time due to excessive heat input and material softening, a sever thinning occurs in weld macrostructure that damages the joint strength.

\subsection{Analyzing weld nugget hardness}

In order to analyze the hardness of weld nugget. The cross section of the joint was prepared and the microhardness was measured in three locations of aluminum side, copper side and interface; then the average of microhardness for each weld sample was reported. Fig. 5 indicates effect of dwell time on hardness of the joint which were fabricated under different tool rotary speed. 
It is seen from the figure that at 1000 RPM tool rotation, the hardness value decreases about $13.8 \%$ by increase in dwell time from $5 \mathrm{~s}$ to $15 \mathrm{~s}$. Also, when the tool rotary speed is $1500 \mathrm{RPM}$, as the dwell time increases, the hardness of weld nugget increases about $16 \%$ and reaches to a maximum value at $15 \mathrm{~s}$. Moreover, at 2000 RPM rotation speed of the tool, the hardness value firstly increases about $12.6 \%$ by increase in dwell time from $5 \mathrm{~s}$ to $10 \mathrm{~s}$; but, by further increase in dwell time from $10 \mathrm{~s}$ to $15 \mathrm{~s}$, the hardness decreases about $10 \%$.

During welding of dissimilar materials. There are two important factors that significantly affect hardness of the weld nugget. One is size of microstructure and two is formation of intermetallic compounds [18]. According to Hall-Petch law, the finer microstructure results to higher hardness values. Also, intermetallic compound is type of ceramic material with high hardness and brittleness that formed under high heat input condition.

At 1000 RPM, tool rotary speed, the heat input is relatively low. Hence, sufficient heat for formation of intermetallic compound isn't provided. In such condition increase in dwell time provides enough time and heat for recrystallization and enlarging the grains in the microstructure. Therefore, the hardness of weld nugget decreases by an increase in dwell time due to formation of coarse microstructure in weld nugget. Fig. 6 illustrates XRD pattern and microstructure of the weld nugget at 1000 RPM tool rotation and different dwell time. It is inferred from the fig. 6 a that no intermetallic compound is formed at 1000 RPM tool rotation and different dwell time. Also, from fig. $6 \mathrm{~b}$ and $6 \mathrm{c}$, it is seen that by increase in dwell time the microstructure of the weld nugget becomes coarser in both the aluminum and copper sides that reduce the hardness value.

It is also found from the fig. 7 that at 1500RPM tool rotation, the hardness increases by increase in the dwell time. When the tool rotation is 1500 RPM, enough heat for formation of intermetallic compound is provided. In such condition by increase in dwell time concentration of thermal energy enhances that causes formation of more intermetallic compound in weld nugget. Therefore, weld nugget hardness increases. Fig. 7 represents XRD pattern of the samples fabricated at tool rotation of 1500RPM under different dwell time. It is seen from the figure at $5 \mathrm{~s}$ dwell time due to low heat input, no intermetallic compound is formed in weld nugget. Also, it is seen when the dwell time is $10 \mathrm{~s}$, compounds such as $\mathrm{Al}_{2} \mathrm{Cu}$ and $\mathrm{Al}_{4} \mathrm{Cu}_{9}$ are seen in the XRD pattern. It is also seen that at $15 \mathrm{~s}$ dwell time, number of peaks in XRD pattern is relatively higher showing more amount of intermetallic compound that exist in the weld nugget.

It is also ascertained from fig. 5 that at 2000 RPM tool rotation, the hardness value firstly increases as dwell time increases from 5 to $10 \mathrm{~s}$. This increase is due to formation another type of intermetallic compound like $\mathrm{Al}_{2} \mathrm{O}_{3}$ ceramic in weld nugget that significantly enhances the hardness value. It is further seen in the figure that as dwell time increases from 10 s to $15 \mathrm{~s}$, the coarse and rough microstructure are formed in weld region. Nevertheless, the ceramic compound formed when dwell time is $15 \mathrm{~s}$, but the roughening effect of microstructure outperforms influence of intermetallic compound that causes low hardness value. Fig. 8 illustrates XRD patterns and microstructure change by dwell time at 2000 RPM 
rotation speed. It is seen from the fig. $8 \mathrm{a}$ at 10 s and 15 s dwell time a new type of intermetallic compound such as alumina is formed in the nugget. Therefore, the hardness increases. Also, from the fig. $8 \mathrm{~b}$ and c, it is observed that increase in dwell time causes coarse microstructure in both sides of aluminum and copper. Thus, a very rough structure damages the mechanical properties of weld nugget and decreases the hardness at $15 \mathrm{~s}$ dwell time.

\subsection{Statistical analysis}

In order to develop empirical relationship between tool rotation sped and dwell time to lap shear strength and hardness response surface methodology is utilized. Design Expert V7 software was utilized here for regression analysis. The analysis of variances (ANOVA) was also carried out to check the validity of developed quadratic model. It was also used to identify which factor has greatest contribution on process quality characteristics. Second order polynomial model of responses including linear, interaction and quadratic terms of tensile strength and hardness are expressed in Eq. 1 and Eq. 2, respectively.

$$
\begin{aligned}
& \operatorname{LSS}(N)=237.3+0.65 N+223.8 t-0066 N t-7.017 t^{2} \\
& H(V)=9.25+0.075 N+1.09 t+0.001 N t-0.137 t^{2}
\end{aligned}
$$

Analysis of variances of lap shear strength and hardness have been presented in Table 2 and 3 , respectively. It is seen in ANOVA tables that the values of $R^{2}$ (i.e. coefficient of determination) is in close agreement with adjusted $\mathrm{R}^{2}$. It describes that the developed models are completely valid to navigate design space [19]. Based on the analysis of variances, it is inferred that the dwell time and tool rotation are most influential factor for lap shear strength and hardness, respectively. Also, the contributions of the significant terms in developing mathematical models of lap shear strength and hardness are shown in Fig. 9. It is seen from the figure that in developing statistical model of the lap shear strength interaction of tool rotation and dwell time has significant influence; while for mathematical model of the hardness, the linear effect of tool rotation is the most significant term.

The developed empirical models can be also used to analyze effect of process factors on lap shear strength and hardness. Hence, the response surfaces of process factors on aforementioned responses were drawn and presented in fig. 10. It is seen from the fig. 10a that the maximum lap shear strength is achievable by selection of 2000 RPM tool rotation and $5 \mathrm{~s}$ dwell time. Furthermore, maximum hardness could be obtained when the tool rotary speed is 2000 RPM and dwell time is 10 s. it is seen that the variation of lap shear strength and hardness by variation of process factors don't follow a similar trend. Thus, to achieve a unified result, its required to find optimal result in a multi-objective optimization problem.

\section{Table 2 ANOVA resits for lap shear strength}




\begin{tabular}{|lllll|}
\hline Source & Sum of squares & Degree of freedom & F-value & Prob $>F$ \\
\hline Model & 246000 & 5 & 11.43 & 0.0029 \\
\hline$N$ & 3952.67 & 1 & 0.92 & 0.3699 \\
\hline$t$ & 37446 & 1 & 8.7 & 0.0214 \\
\hline$N \times t$ & 109600 & 1 & 25.45 & 0.0015 \\
\hline$N^{2}$ & 104 & 1 & 0.024 & 0.8839 \\
$t^{2}$ & 83486 & 1 & 19.39 & 0.0031 \\
\hline $\mathrm{R}^{2}=0.9358$ & & $\mathrm{R}_{\text {Adjusted }}=0.9188$ & \\
\hline
\end{tabular}

\section{Table 3 ANOVA results for hardness}

\begin{tabular}{|lllll|}
\hline Source & Sum of squares & Degree of freedom & F-value & Prob>F \\
\hline Model & 601.47 & 5 & 6.87 & 0.0125 \\
$N$ & 368.17 & 1 & 21.03 & 0.0025 \\
$t$ & 2.67 & 1 & 0.15 & 0.7 \\
$N \times t$ & 36 & 1 & 2.06 & 0.1947 \\
$N^{2}$ & 94.5 & 1 & 5.39 & 0.053 \\
\hline$t^{2}$ & 30.9 & 1 & 1.77 & 0.2259 \\
$\mathrm{R}^{2}=0.9591$ & & $\mathrm{R}_{\text {Adjusted }}=0.9349$ & \\
\hline
\end{tabular}

Multi-characteristics optimization was carried out by desirability function. The toolbox of this method in Design expert software was adjusted based on range of process factors and criteria which were specified in Table 4. By performing the optimization in the software, the obtained results are identified and presented in Table 5. It is seen from table, illustrates the optimum solution that obtained through desirability function. It is evident from the table that setting of 1972 RPM tool rotation and $8.38 \mathrm{~s}$ dwell time is the most optimal solution that causes desirability of $85.6 \%$ with strength value of $1894 \mathrm{~N}$ and hardness of $84 \mathrm{~V}$. The obtained solution should be experimentally verified to show applicability of proposed approach in optimization of FSSW process. The results of confirmatory experiment have been also presented in table 4. It is found from this table that the error values for both of lap shear strength and hardness are less than $8 \%$ that shows the excellent agreement with actual and predicted values.

\section{Table 4 Optimization criterion}




\begin{tabular}{|c|c|c|}
\hline Factors/Responses & Criterion & Importance \\
\hline Tool rotation (RPM) & In range of $1000-200$ & - \\
\hline Dwell time (s) & In range of 5-10 & - \\
\hline Lap shear strength $(\mathrm{N})$ & Maximize & $\star \star \star \star \star \star(5)$ \\
\hline Hardness (V) & Minimize & 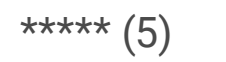 \\
\hline
\end{tabular}

Table 5 Optimum parameter setting along with validation test results

\begin{tabular}{|c|c|c|c|c|c|c|c|c|}
\hline \multicolumn{2}{|l|}{ Factor } & \multicolumn{3}{|c|}{ Lap shear strength $(\mathrm{N})$} & \multicolumn{3}{|l|}{ Hardness (V) } & \multirow{2}{*}{$\begin{array}{l}\text { Objective } \\
\text { Desirability }\end{array}$} \\
\hline N (RPM) & $t(s)$ & Experiment & Model & Error & Experiment & Model & Error & \\
\hline 1982 & 8.3 & 1803 & 1894 & 0.05 & 78 & 84 & 0.076 & 0.856 \\
\hline
\end{tabular}

\section{Conclusion}

In the present study, lap joints of dissimilar 5052 aluminum alloy and pure copper were fabricated by friction stir spot welding process. Microstructural evolution and XRD pattern of fabricated samples were obtained to analyze the mechanical properties such as lap shear strength and hardness. Also, statistical analyzes were made to identify contribution of parameter in determining of significant terms and optimal parameter setting regarding desired quality characteristics. The obtained results can be summarized as follows:

- It is found from the results that sound joints with high lap shear strength is obtained when the tool rotation is 2000 RPM and swell time is 5 s.

- The microstructure of the FSP region at 2000 RPM and 5s dwell time showed uniform dispersion of $\mathrm{Cu}$ in aluminum matrix and no metallurgical defect was observed in macrostructure.

- From the obtained microhardness results, it is found that tool rotation of 2000 RPM and dwell time of 10 s causes highest hardness in weld nugget including aluminum side, copper side and interface.

- The types of intermetallic compound in the sample at 2000 RPM tool rotation and 10 s dwell time were $\mathrm{Al}_{2} \mathrm{Cu}, \mathrm{Al}_{4} \mathrm{Cu}_{9}$ and $\mathrm{Al}_{2} \mathrm{O}_{3}$ significantly increases the hardness.

- From statistical analysis, it was identified that dwell time and tool rotation are the most influential factor affecting lap shear strength and hardness, respectively.

- Multi-objective optimization of process parameters showed that achieving simultaneous maximum strength and hardness is possible by selection of 2000 RPM tool rotation and $8.3 \mathrm{~s}$ dwell time. The desirability of optimum results was about $86 \%$ and the prediction error for the quality characteristics was less than $8 \%$.

\section{Declarations}


Ethical approval: It is approved that the paper is original and has been written based on authors own finding. All the figures and tables are original and every expression from other published works were acknowledged and referenced.

Consent to participate: It is confirmed that all the authors are aware and satisfied from authorship order and correspondence of the paper

Consent to Publish: All the authors are satisfied with authorship order in publication process

\section{Authors Contributions:}

- Aydin Jadidi: $40 \%$ contribution in writing the paper and doing research

- Reza Bagherian Azhiri: 30\% contribution in analyzing the results and supervision

- Amir Baghdadchi: 20\% contribution in designing facilities;

- Abolfazl Salmani Bideskan: 10\% contribution in providing materials and testing and editing the language

Funding: The authors receive no financial support from any specific organization to perform research

Competing Interests: It is declared that there is no conflict of interest in authorship and data provided.

Availability of data and materials: It is confirmed that the data and materials can be available after publication on the basis of springer nature rights and access.

\section{References}

1. Ouyang, J., Yarrapareddy, E., \& Kovacevic, R. (2006). Microstructural evolution in the friction stir welded 6061 aluminum alloy (T6-temper condition) to copper. Journal of Materials Processing Technology, 172(1), 110-122.

2. Sun, Z., \& Karppi, R. (1996). The application of electron beam welding for the joining of dissimilar metals: an overview. Journal of Materials Processing Technology, 59(3), 257-267.

3. Kahraman, N., Gülenç, B., \& Findik, F. (2005). Joining of titanium/stainless steel by explosive welding and effect on interface. Journal of Materials Processing Technology, 169(2), 127-133.

4. Abbasi, M., Taheri, A. K., \& Salehi, M. T. (2001). Growth rate of intermetallic compounds in Al/Cu bimetal produced by cold roll welding process. Journal of Alloys and Compounds, 319(1), 233-241.

5. Uzun, H., Dalle Donne, C., Argagnotto, A., Ghidini, T., \& Gambaro, C. (2005). Friction stir welding of dissimilar Al 6013-T4 to X5CrNi18-10 stainless steel. Materials \& design, 26(1), 41-46.

6. Murr, L. E., Li, Y., Trillo, E. A., Flores, R. D., \& McClure, J. C. (1998). Microstructures in friction-stir welded metals. Journal of materials processing and manufacturing science, 7, 145-161.

7. Xue, P., Xiao, B. L., Ni, D. R., \& Ma, Z. Y. (2010). Enhanced mechanical properties of friction stir welded dissimilar Al-Cu joint by intermetallic compounds. Materials Science and Engineering: A, 527(21), 
5723-5727.

8. Xue, P., Ni, D. R., Wang, D., Xiao, B. L., \& Ma, Z. Y. (2011). Effect of friction stir welding parameters on the microstructure and mechanical properties of the dissimilar $\mathrm{Al}-\mathrm{Cu}$ joints. Materials science and engineering: $A, 528(13), 4683-4689$.

9. Tan, C. W., Jiang, Z. G., Li, L. Q., Chen, Y. B., \& Chen, X. Y. (2013). Microstructural evolution and mechanical properties of dissimilar $\mathrm{Al}-\mathrm{Cu}$ joints produced by friction stir welding. Materials \& Design, 51, 466-473.

10. LI, X. W., ZHANG, D. T., Cheng, Q. I. U., \& ZHANG, W. (2012). Microstructure and mechanical properties of dissimilar pure copper/1350 aluminum alloy butt joints by friction stir welding. Transactions of Nonferrous Metals Society of China, 22(6), 1298-1306.

11. Galvão, I., Loureiro, A., Verdera, D., Gesto, D., \& Rodrigues, D. M. (2012). Influence of tool offsetting on the structure and morphology of dissimilar aluminum to copper friction-stir welds. Metallurgical and Materials Transactions A, 43(13), 5096-5105.

12. Galvão, I., Leitão, C., Loureiro, A., \& Rodrigues, D. M. (2012). Study of the welding conditions during similar and dissimilar aluminium and copper welding based on torque sensitivity analysis. Materials \& Design, 42, 259-264.

13. Muthu, M. F. X., \& Jayabalan, V. (2015). Tool travel speed effects on the microstructure of friction stir welded aluminum-copper joints. Journal of Materials Processing Technology, 217, 105-113.

14. Saeid, T., Abdollah-Zadeh, A., \& Sazgari, B. (2010). Weldability and mechanical properties of dissimilar aluminum-copper lap joints made by friction stir welding. Journal of Alloys and Compounds, 490(1), 652-655.

15. Zhang, J., Shen, Y., Yao, X., Xu, H., \& Li, B. (2014). Investigation on dissimilar underwater friction stir lap welding of 6061-T6 aluminum alloy to pure copper. Materials \& Design, 64, 74-80.

16. Elangovan, K., \& Balasubramanian, V. (2007). Influences of pin profile and rotational speed of the tool on the formation of friction stir processing zone in AA2219 aluminium alloy. Materials Science and Engineering: A, 459(1), 7-18.

17. Elangovan, K., Balasubramanian, V., \& Valliappan, M. (2008). Influences of tool pin profile and axial force on the formation of friction stir processing zone in AA6061 aluminium alloy. The international journal of advanced manufacturing technology, 38(3-4), 285-295.

18. Rajakumar, S., Muralidharan, C., \& Balasubramanian, V. (2011). Predicting tensile strength, hardness and corrosion rate of friction stir welded AA6061-T 6 aluminum alloy joints. Materials \& Design, 32(5), 2878-2890.

19. Khanghah SP, Boozarpoor M, Lotfi M, Teimouri R. Optimization of micro-milling parameters regarding burr size minimization via RSM and simulated annealing algorithm. Transactions of the Indian Institute of Metals. 2015 Oct;68(5):897-910.

20. Teimouri R, Amini S, Lotfi M, Alinaghian M. Sustainable drilling process of 1045 steel plates regarding minimum energy consumption and desired work quality. International Journal of Lightweight Materials and Manufacture. 2019 Dec 1;2(4):397-406. 
Figures

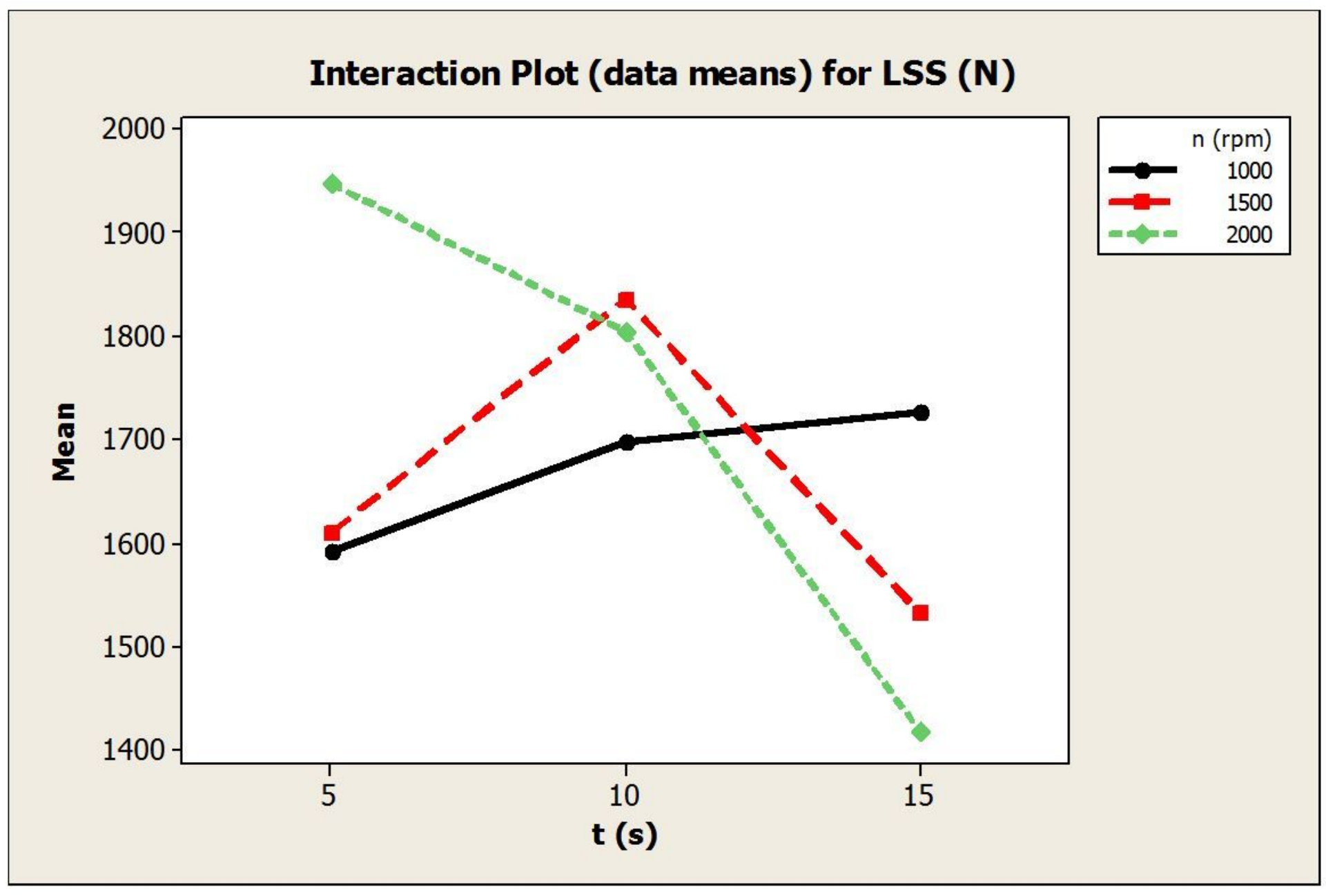

Figure 1

Simultaneous effect of tool rotation speed and dwell time on lap shear strength 

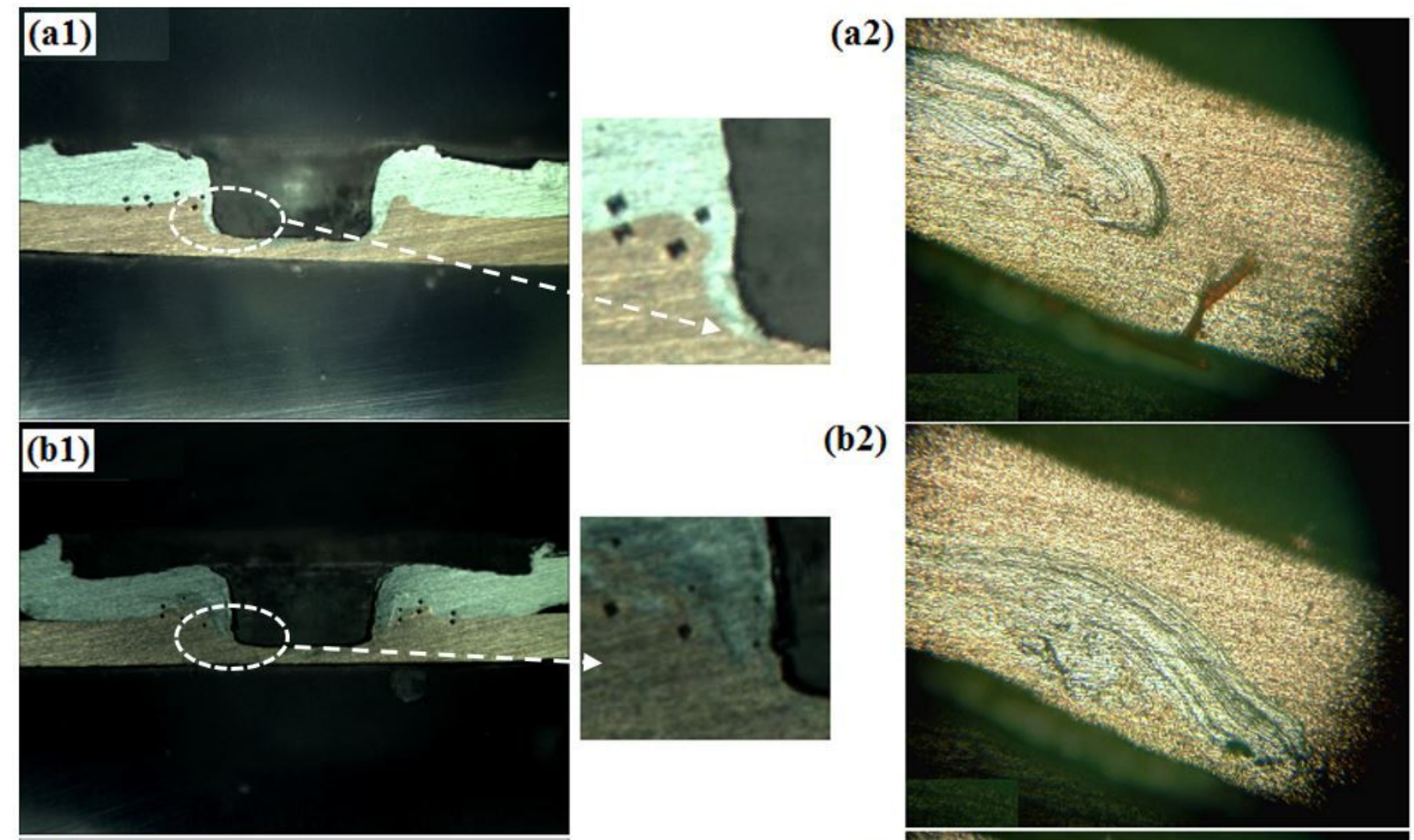

(b2)
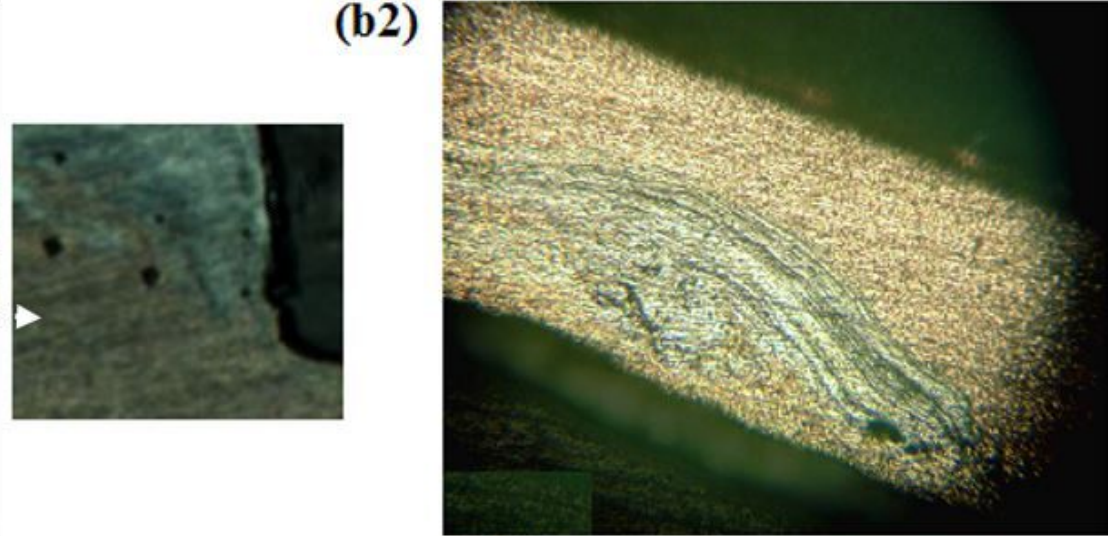

\section{(c1)}
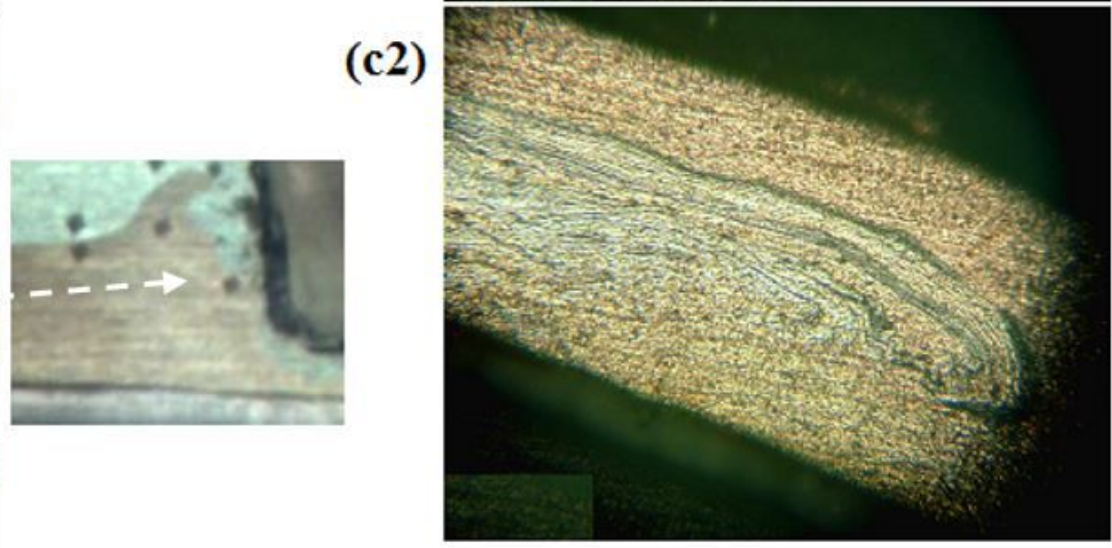

\section{Figure 2}

Macrostructure and microstructure of FSP region at tool rotation of 1000 RPM and different dwell time (a) $5 \mathrm{~s}$ (b) $10 \mathrm{~s}(\mathrm{c}) 15 \mathrm{~s}$ 
(a)

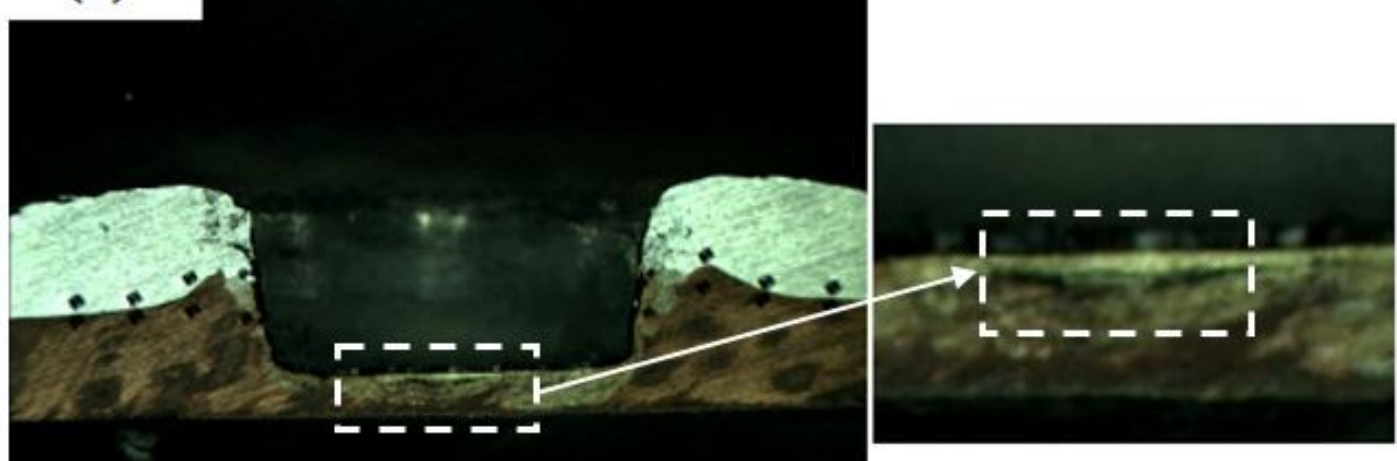

(b)

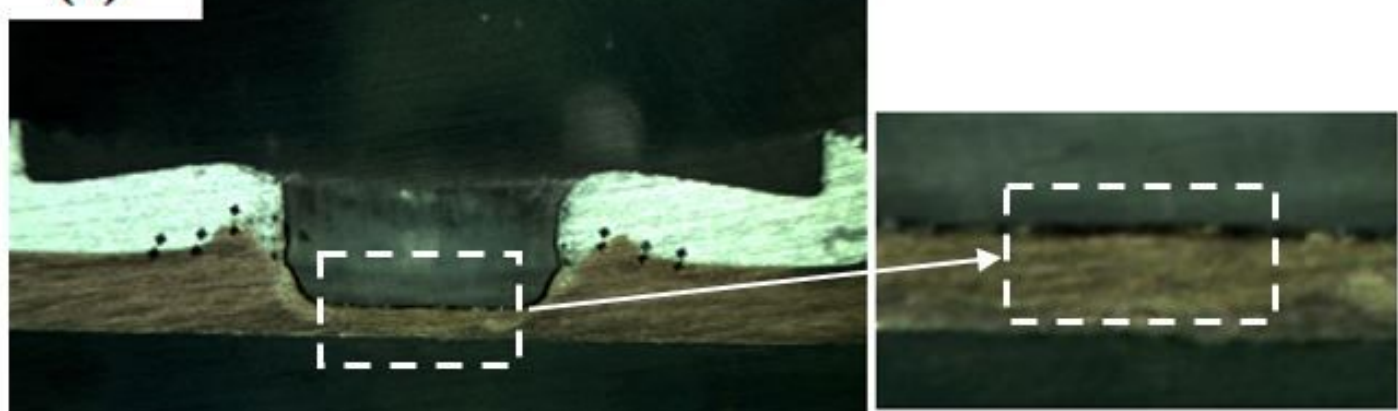

(c)

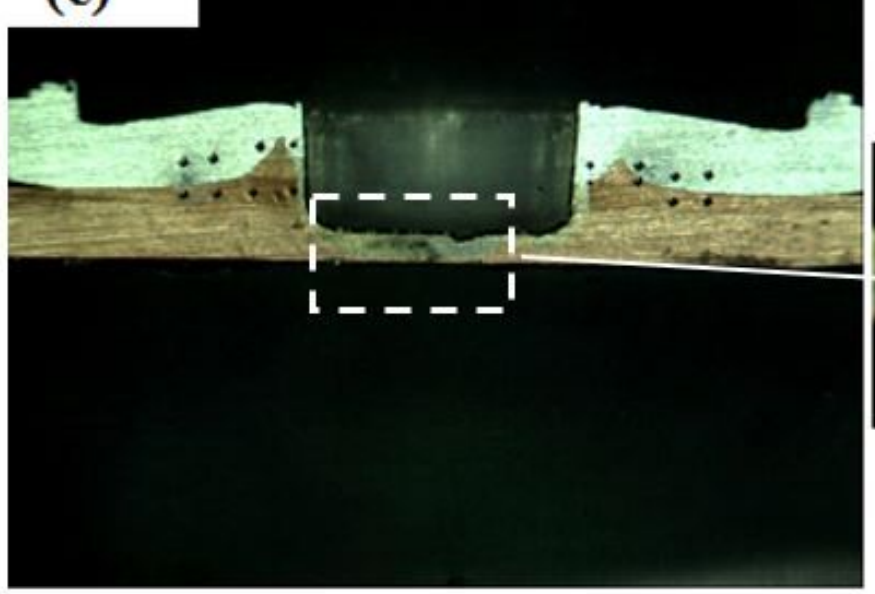

1------

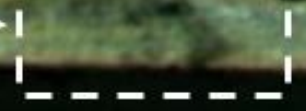

\section{Figure 3}

Macrostructure of the weld region at rotation of 1500 RPM and different dwell time (a) $5 \mathrm{~s}$ (b) $10 \mathrm{~s}$ (c) $15 \mathrm{~s}$ 

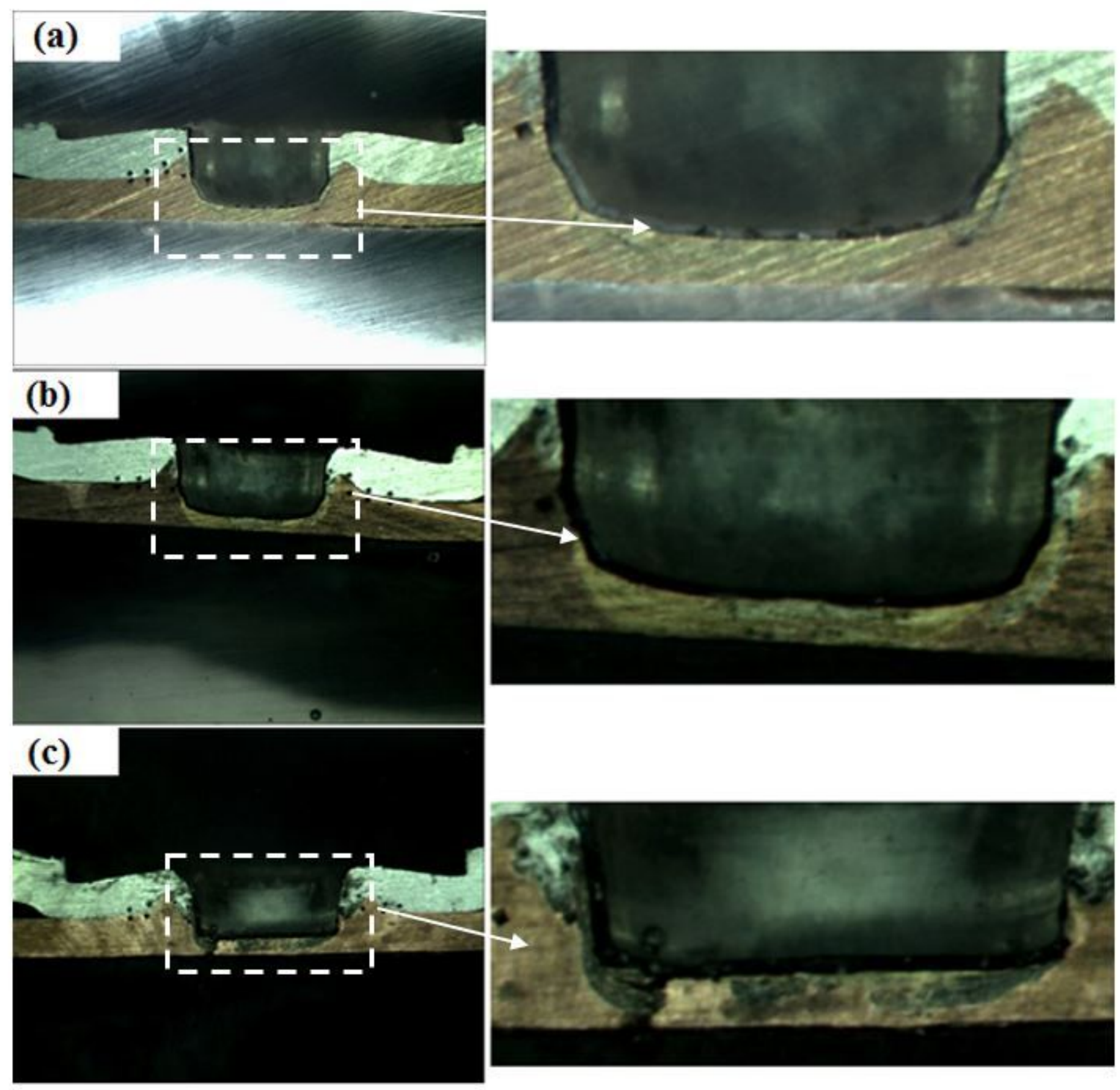

Figure 4

Macrostructure of the weld region at rotation of 2000 RPM and different dwell time (a) $5 \mathrm{~s}$ (b) $10 \mathrm{~s}$ (c) $15 \mathrm{~s}$ 


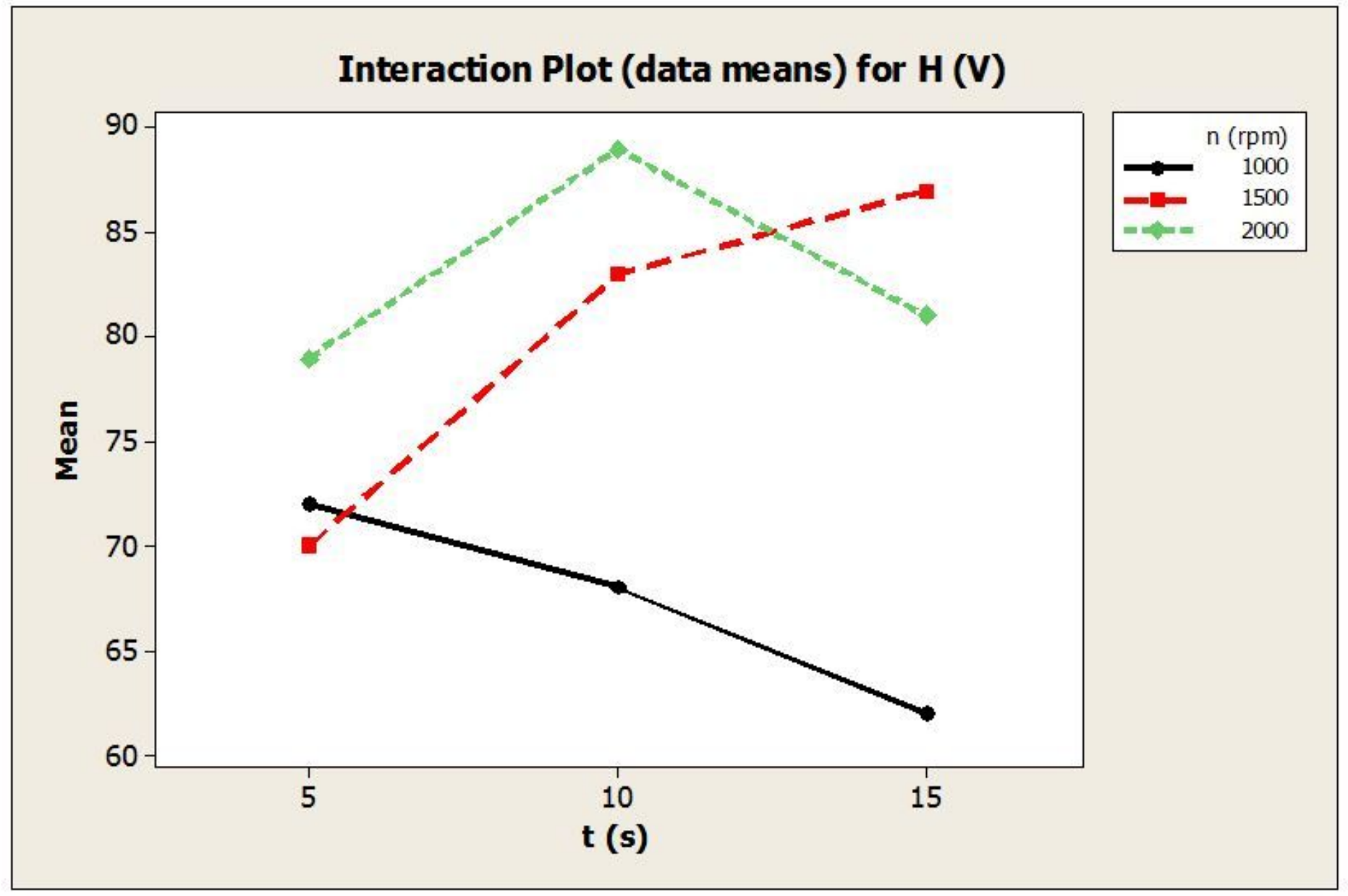

Figure 5

Simultaneous effect of tool rotation speed and dwell time on weld nugget hardness 

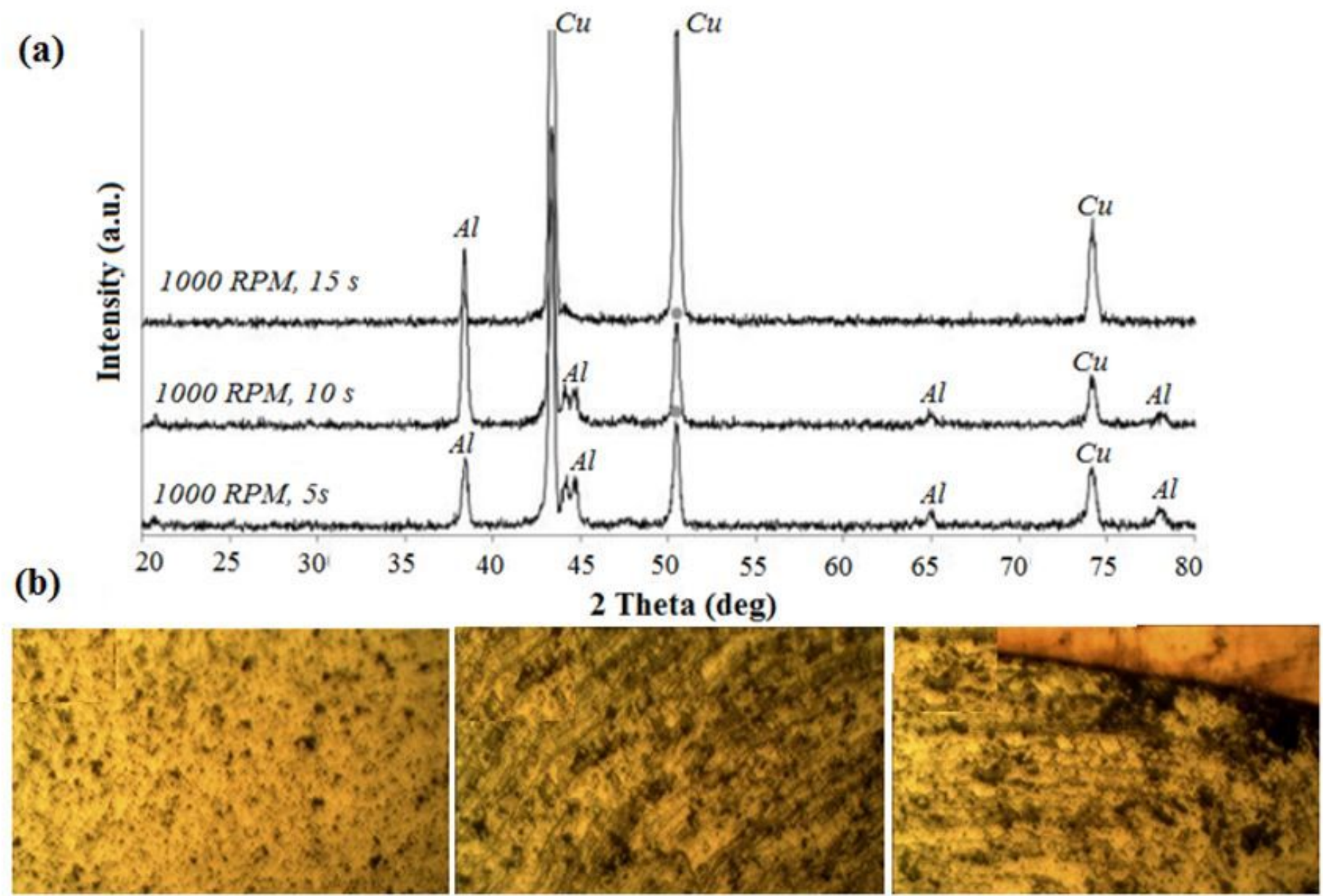

(c)

$5 s$

$10 \mathrm{~s}$

$15 s$
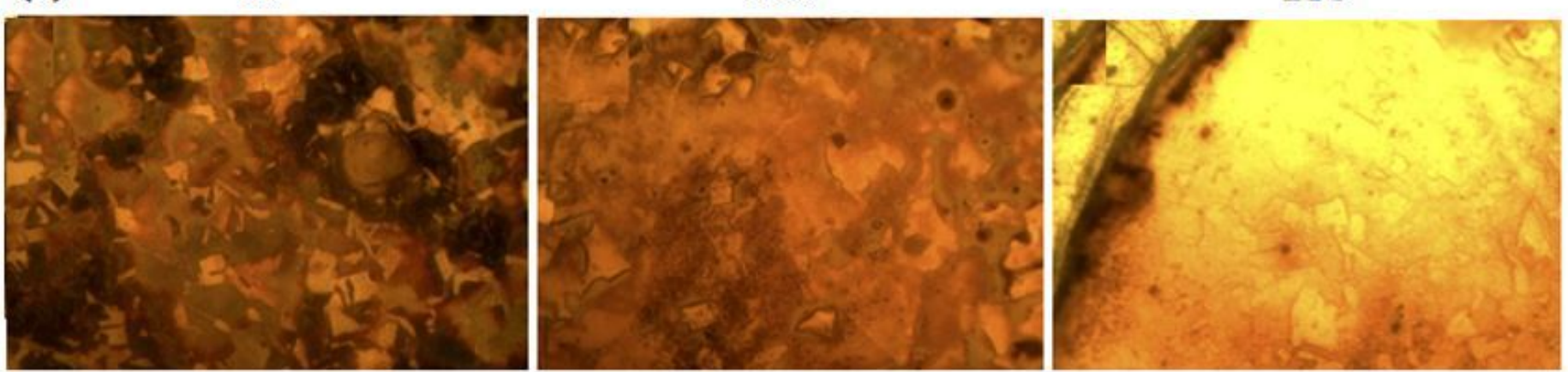

Figure 6

(a) XRD pattern of the sample at 1000 RPM (b) Microstructure of the aluminum side (c) Microstructure of the copper side 


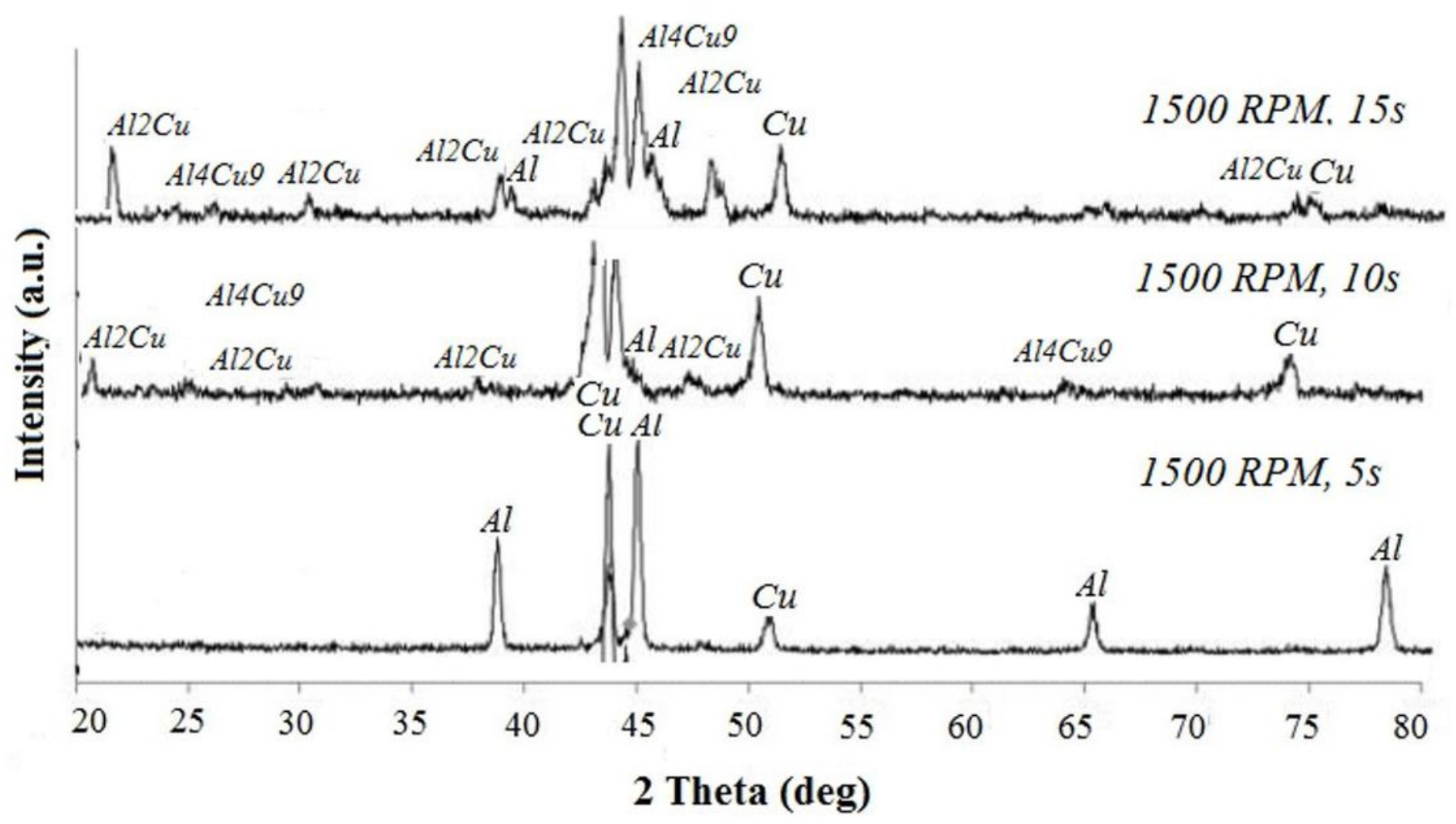

Figure 7

XRD pattern of samples at 1500 RPM tool rotation under different dwell time 
(a)

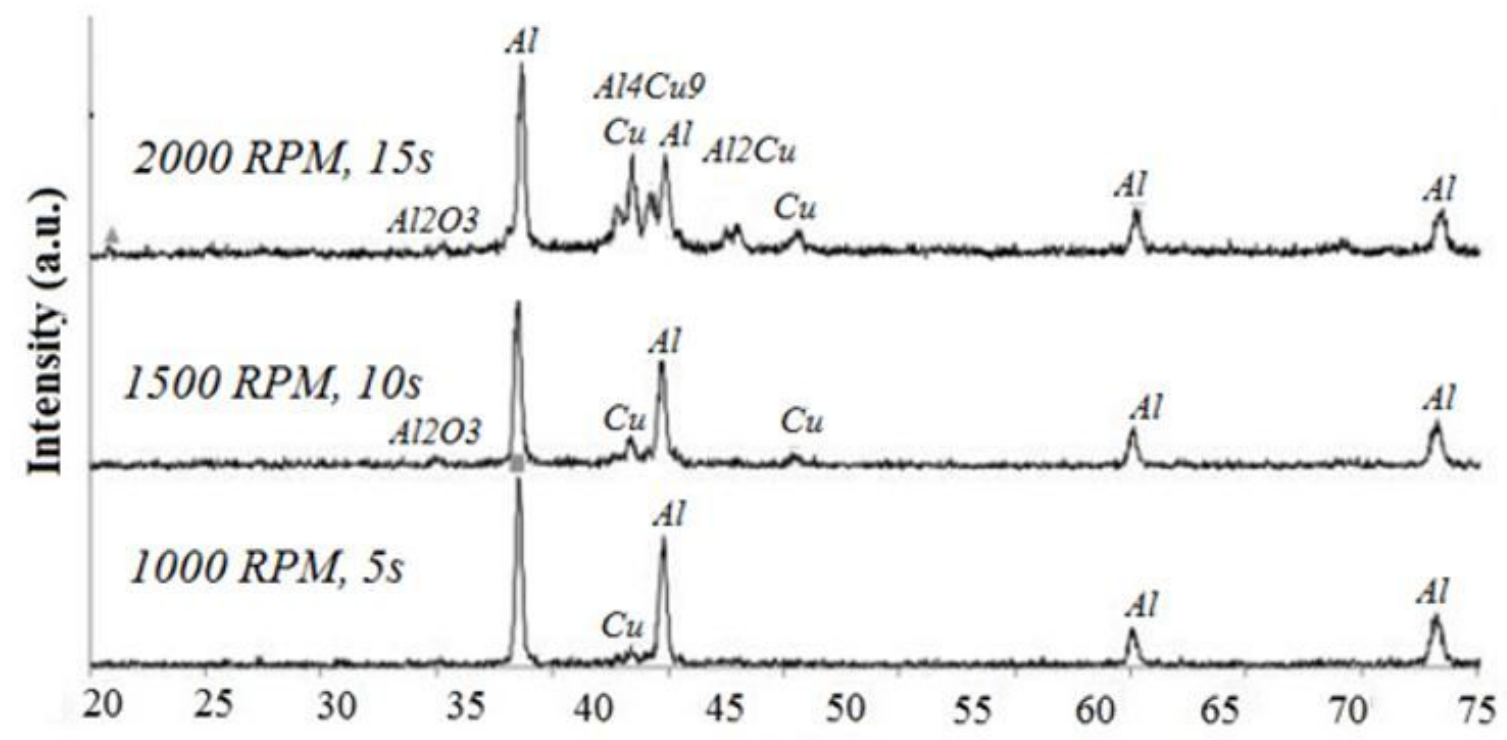

(b)

\section{Theta (deg)}

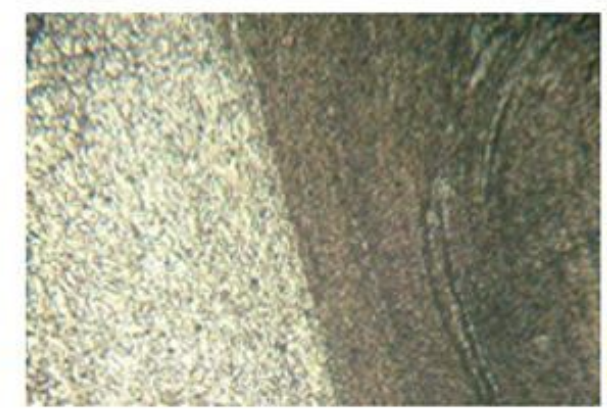

(c)

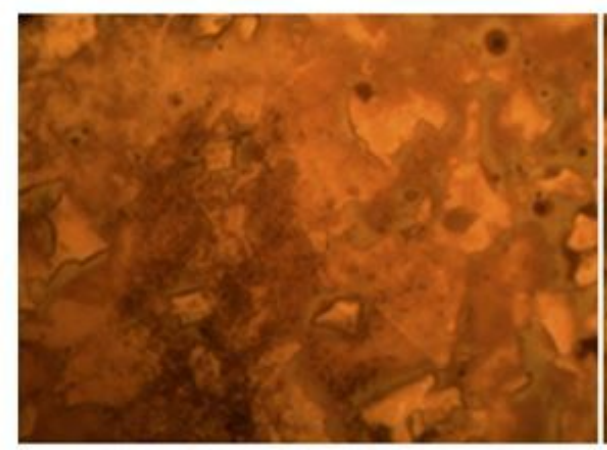

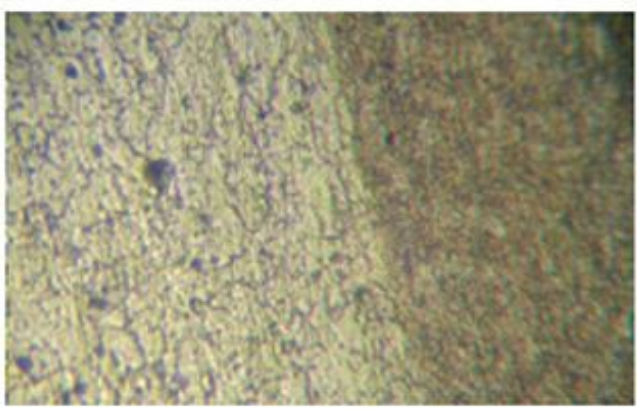

$10 \mathrm{~s}$

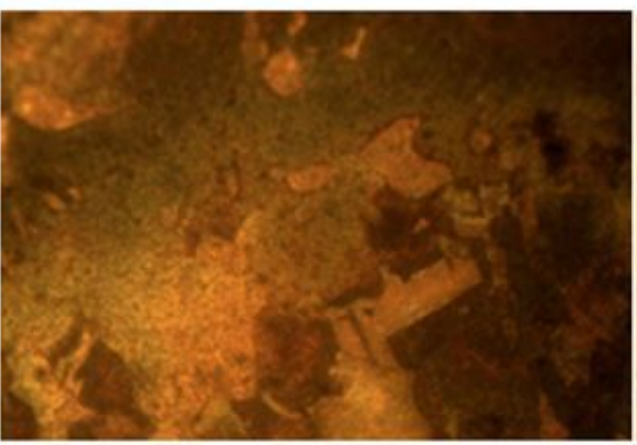

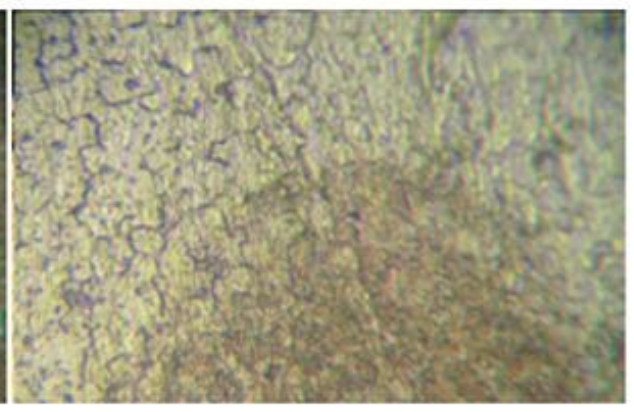

$15 \mathrm{~s}$

\section{Figure 8}

(a) XRD pattern of the sample at 2000 RPM (b) Microstructure of the aluminum side (c) Microstructure of the copper side 
(a)

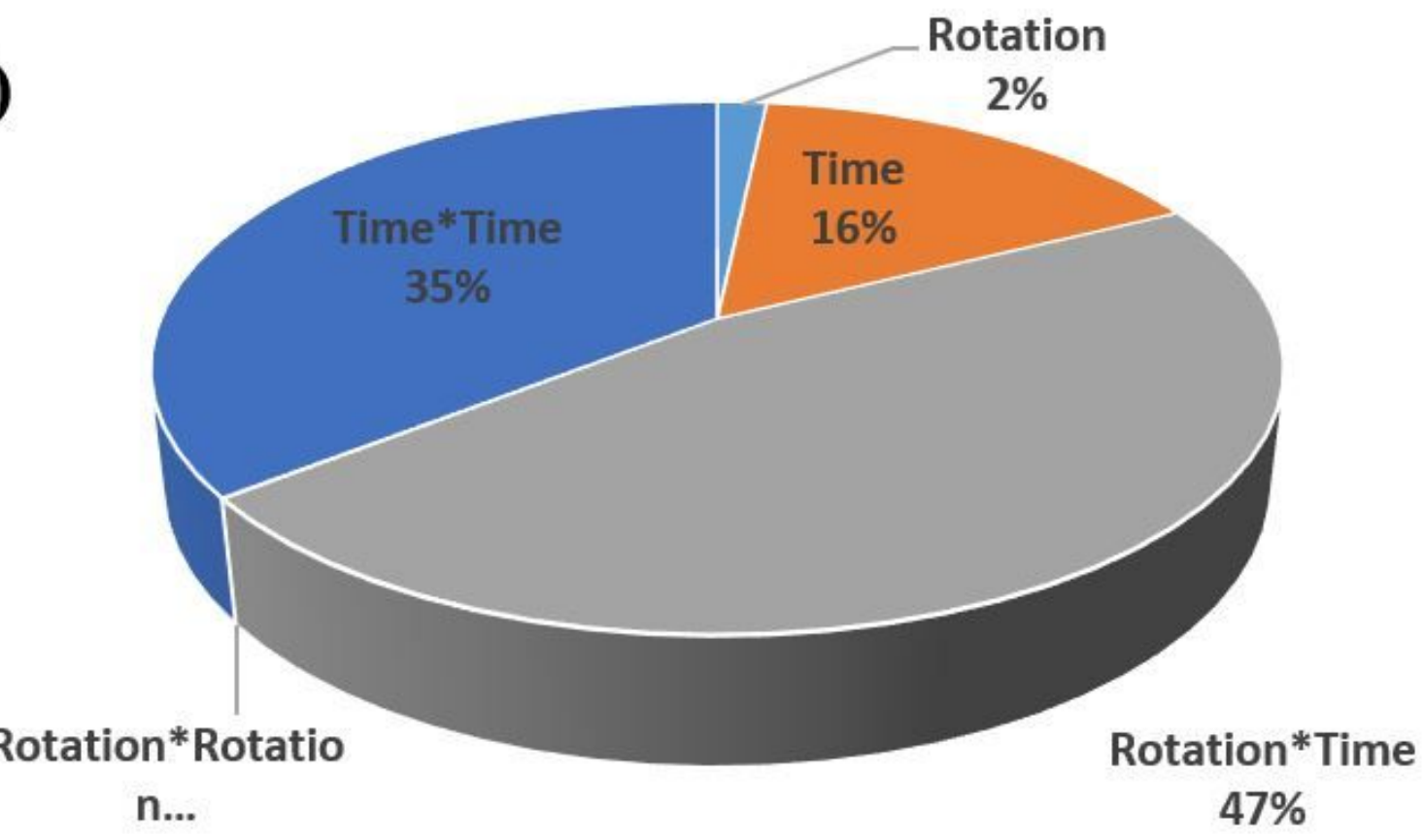

(b) Rotation* Rotat Time*Time

$6 \%$

Rotation*Time $7 \%$

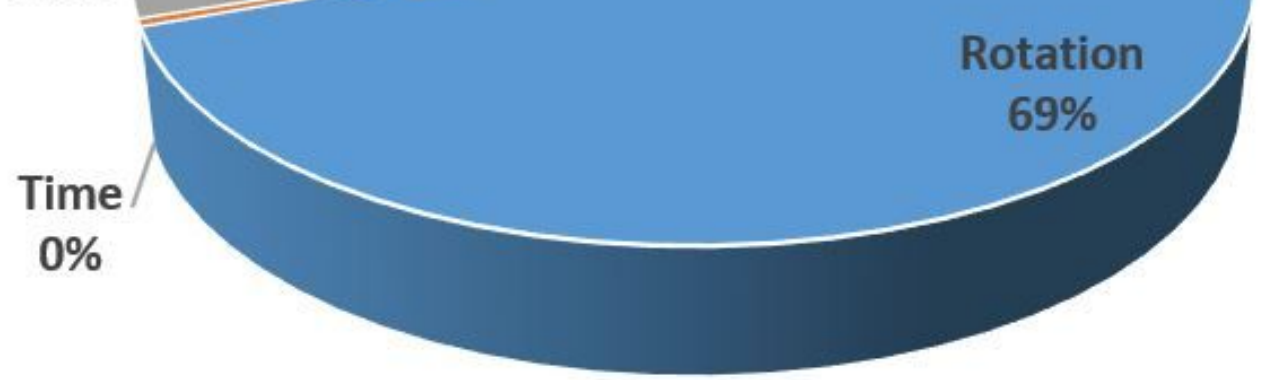

Figure 9

Pie graphs showing contribution of model terms in (a) lap shear strength (b) hardness 


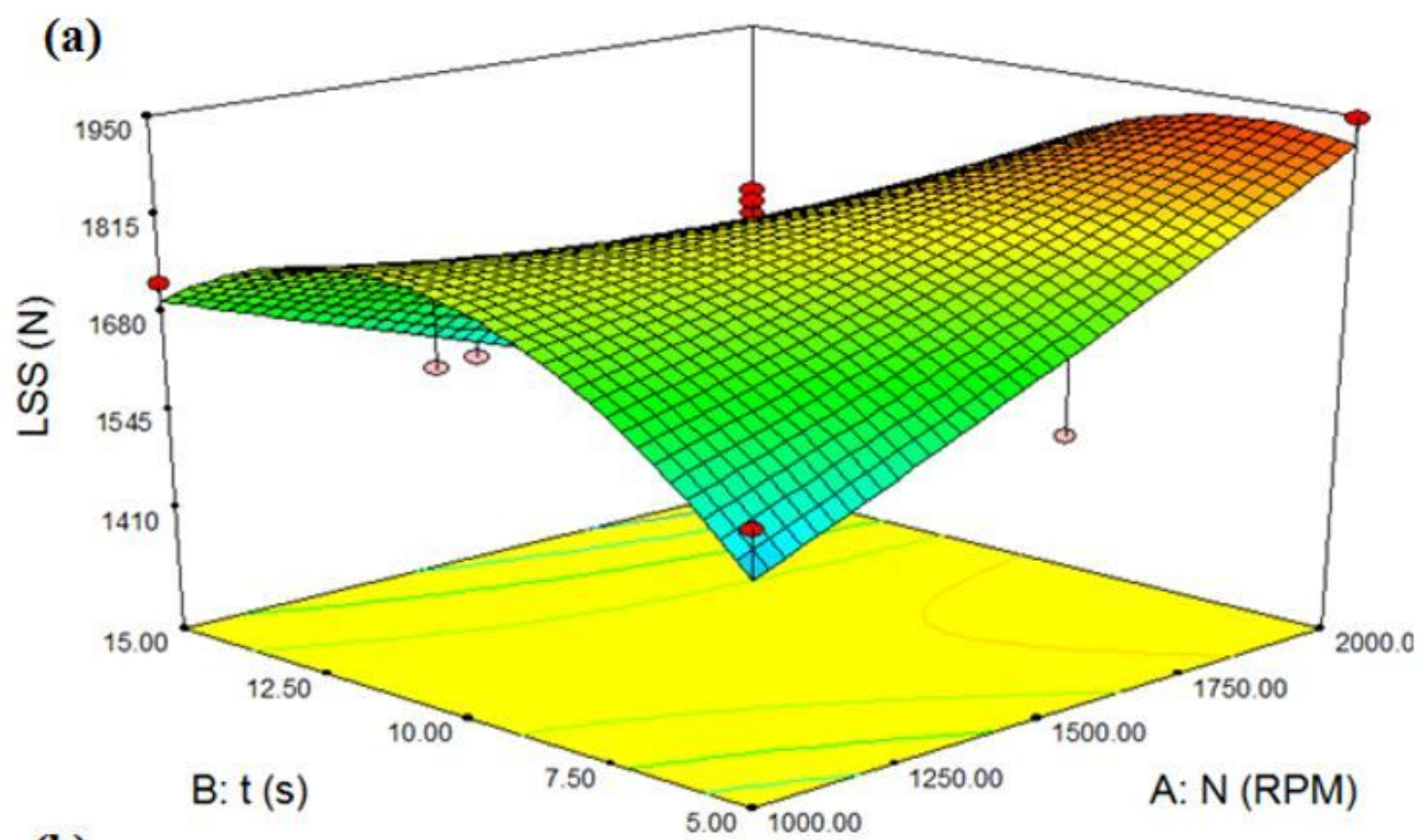

(b)

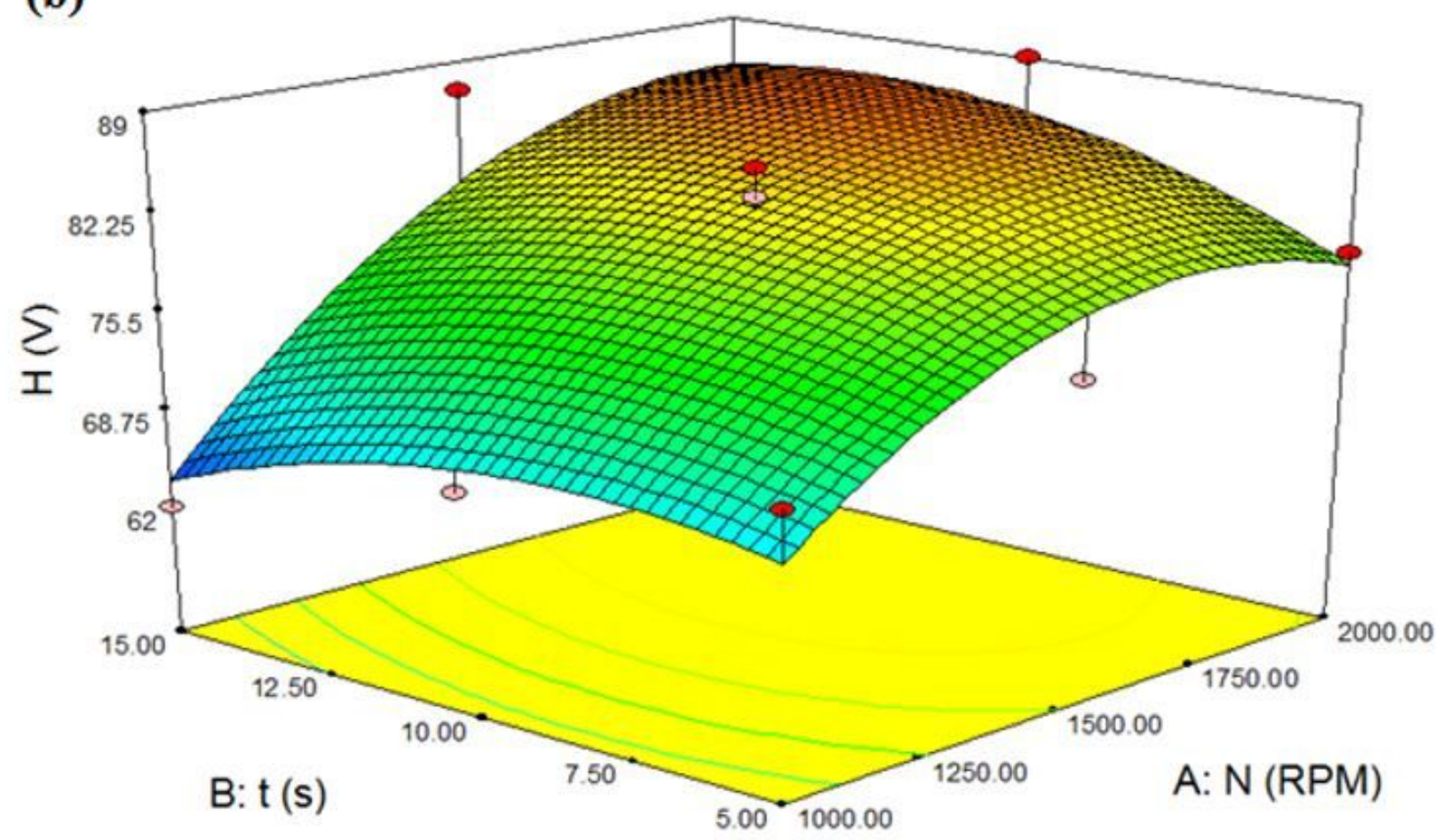

Figure 10

Response surface of tool rotation and dwell time on (a) lap shear strength (b) hardness 